\title{
A Morphometric Study of Dry Human Typical Thoracic Vertebral Body in Telangana Region.
}

\author{
Dr. M.vasantha ${ }^{1}$,Dr. P. Koteswara $\operatorname{rao}^{2}$, Dr. V.janaki ${ }^{3}$ \\ ${ }^{1}$ Associate Professor, Dept Of Anatomy, Kakathiya Medical College, Warangal,. Telangana State. \\ ${ }^{2}$ Retired Civil Surgeon, Medical Officer Uhtc -Urban Health Training Centre, Appollo Institute Of Medical \\ Sciences And Research, Shaik Pet, Nala, Hyderabad, Telangana State. \\ ${ }^{3}$ Associate Professor ,Dept Of Anatomy, Kakathiya Medical College, Warangal, Telangana State.
}

\begin{abstract}
:
Background: Previous studies in the past about morphometry of thoracic vertebrae mainly focused on pedicle diameters and their angulations. The vertebral body were not studied particularly in Telangana Region that is the reason the present study has given importance to the morphometry of vertebral body.

Objective: To measure the various parameters of vertebral body in typical thoracic vertebrae by using vernier caliper.

Material and methods: Hundred dry human typical thoracic vertebrae of undetermined gender and age were selected for the study. The various parameters of vertebral body were measured.

Results: The anteroposterior distance of the vertebral body in typical thoracic vertebrae ranged from $15-29$ $\mathrm{mm}$ with a mean of $21.96 \mathrm{~mm}$. The vertebral body superior width ( superior transeverse diameter) ranged from $23-32 \mathrm{~mm}$ with a mean of $24.4 \mathrm{~mm}$. The vertebral body inferior width (inferior trasverse diameter) ranged from $25-38 \mathrm{~mm}$ with a mean of $31.4 \mathrm{~mm}$. The anterior height (mid sagital) of the body ranged from $14-20 \mathrm{~mm}$ with a mean of $17.71 \mathrm{~mm}$. The Rt \& Lt. lateral height of the body ranged from $14-21 \mathrm{~mm}$ with a mean of 18.01 $\mathrm{mm}$.

Conclusion: The results provide information for more accurate modelling and design of vertebral body implants and instrumentations for Indian population.
\end{abstract}

Keywords: Anterior height, Posterior height, Vertebral body width, Typical thoracic vertebra

\section{Introduction}

The adult vertebral column (also called the spine or spinal column) usually consists of 33 vertebral segments- 7 cervical, 12 thoracic, 5 lumbar, 5 sacral and 4 coccygeal. The functions of the column are to support the trunk, to protect the spinal cord and nerves, and to provide attachments for muscles. It is also an important site of haematopoiesis throughout life ${ }^{(1)}$.The vertebrae can be involved in various conditions. These include fractures, infections, malignancies and inflammatory disorders. Abnormal curvatures of the vertebral column in the thoracic region such as kyphosis and scoliosis may result from developmental anomalies or pathological processes involving vertebrae ${ }^{(2)}$.The vertebral bodies and the intervertebral discs form an important column in transmission of weight of the body. In the upper thoracic region, due to the anterior curvature, the main part of the compressive force is transmitted through the anterior column formed vertebral body and intervertebral disc, with resulting increased stress ${ }^{(3)}$. The compressive force in the lower thoracic region is transmitted through two parallel columns, one anterior and one posterior formed by successive articulations of laminae with each other ${ }^{(4)}$.In recent years, there have been considerable developments in instrumentation designed to stabilize and correct the thoracic spine ${ }^{(5)}$. Anterior inter body fusion, in association with a variety of methods to stabilize both the implant and motion segment, has increased in popularity. Hence, the present study measured the various dimensions of vertebral body.

\section{Material And Methods}

The study was conducted on dry human typical thoracic vertebrae. The vertebrae were obtained from the bone collection of the Department of Anatomy of Osmania and Kakathiya Medical College in Telangana Region. 100 undamaged typical thoracic vertebrae were selected for the study. The vertebrae were of undetermined gender and age. Each vertebra was assigned a serial number. Anatomical measurements were taken on these specimens using a verniercaliper.

The following parameters were recorded in a proforma:

1. Anteroposterior distance of the vertebral body- It is the distance between anterior border and posterior border of the superior surface of vertebral body in midline. 
2. Superior transverse diameter of the vertebral body- It is the maximum transverse diameter of the vertebral body at the superior surface.

3. Inferior transverse diameter of the vertebral body- It is the maximum transverse diameter of the vertebral body at the inferior surface.

4. Anterior height (mid sagital) of the body- It is the vertical distance between superior and inferior surface of body in the midline anteriorly.

5. Rt and Lt lateral height of the body- It is the vertical distance between superior and inferior surface of body in the lateral side of vertebra.

\section{Results}

1. The anteroposterior distance of the vertebral body in typical thoracic vertebrae ranged from $15-29 \mathrm{~mm}$ with a mean of $21.96 \mathrm{~mm}$.

2. Superior transverse diameter of the vertebral body- It is the maximum transverse diameter of the vertebral body at the superior surface ranged from $23-32 \mathrm{~mm}$ with a mean of $24.4 \mathrm{~mm}$.

3. Inferior transverse diameter of the vertebral body- It is the maximum transverse diameter of the vertebral body at the inferior surface ranged from $25-38 \mathrm{~mm}$ with a mean of $31.4 \mathrm{~mm}$.

4. Anterior height of the body- It is the vertical distance between superior and inferior surface of body in the midline anteriorly ranged from $14-20 \mathrm{~mm}$ with a mean of $31.4 \mathrm{~mm}$.

5. Rt and Lt lateral height of the body- It is the vertical distance between superior and inferior surface of body in the lateral side of vertebra ranged from $14-21 \mathrm{~mm}$ with a mean of $18.01 \mathrm{~mm}$.

\section{Discussion}

Several quantitative anatomical studies have been carried out for thoracic vertebrae in different countries. Many authors have studied the vertebrae using different methods such as plain radiographs, direct specimen measurements and quantitative 3 dimensional anatomic techniques. These include Panjabi MM et $\mathrm{a}^{(6)}$, Tan et $\mathrm{a}^{(7)}$, Roop Singh et $\mathrm{a}^{(8)}$, Gupta R et al ${ }^{(9)}$, Kunkel ME et al ${ }^{(10)}$ and Patil Dhaval K. et al ${ }^{(12)}$. However, Berry $\mathrm{JL}$ et $\mathrm{al}^{(11)}$ studied only second and seventh thoracic vertebrae. The following tables present the comparison of means of the various parameters obtained from previous studies with that of the present study.

Table 1: Comparison of mean anteroposterior distance of the vertebral body in typical thoracic vertebrae with other studies.

\begin{tabular}{|l|l|l|l|l|}
\hline Study & Year & Country & Material for study & Mean (in mm) \\
\hline Panjabi MM et al ${ }^{(6)}$ & 1991 & USA & Dry bones & 24.26 \\
\hline Tan et al ${ }^{(7)} 2004$ & 2004 & Singapore & Dry bones & 20.21 \\
\hline $\begin{array}{l}\text { Patil Dhaval K. et } \\
\mathrm{al}^{(12)}\end{array}$ & 2014 & India & Dry bones & 20.78 \\
\hline Present study & 2017 & $\begin{array}{l}\text { Telangana- } \\
\text { India }\end{array}$ & Dry bones & $21-96$ \\
\hline
\end{tabular}

When compared, the mean anteroposterior distance of the vertebral body in the present study is lesser than the value found by Panjabi MM et $\mathrm{al}^{(6)}$ but is in greater than with the finding of Tan et $\mathrm{a}^{(7)}$.

Table 2: Comparison of mean transverse diameter of the vertebral body in typical thoracic vertebrae with other studies.

\begin{tabular}{|c|c|c|c|c|}
\hline Study & Year & Country & Material for study & Mean (in mm) \\
\hline Panjabi MM et al ${ }^{(6)}$ & 1991 & USA & Dry bones & 26.06 \\
\hline Tan et $\mathrm{al}^{(7)}$ & 2004 & India & Dry bones & 23.84 \\
\hline Singh $\mathrm{R}$ et $\mathrm{al}^{(8)}$ & 2011 & India & Dry bones & 25.9 \\
\hline Patil Dhaval K. et al ${ }^{(12)}$ & 2014 & India & Dry bones & 27.02 \\
\hline Present study & 2016 & India & Dry bones & 27.9 \\
\hline
\end{tabular}

The mean transverse diameter of the vertebral body in the present study is slightly greater that of the earlier studies. 
Table 3: Comparison of mean anterior height of the body in typical thoracic vertebrae with other studies.

\begin{tabular}{|l|l|l|l|l|}
\hline Study & Year & Country & Material for study & Mean (in mm) \\
\hline Tan et al ${ }^{(7)}$ & 2004 & Singapore & Dry bones & 15.04 \\
\hline Kunkel ME et al ${ }^{(10)}$ & 2011 & Germany & Cadaveric, Radiographic & 15.84 \\
\hline Singh R et al ${ }^{(8)}$ & 2011 & India & Dry bones & 17.39 \\
\hline $\begin{array}{l}\text { Patil Dhaval K. et } \\
\text { al }^{(12)}\end{array}$ & 2014 & India & Dry bones & 17.17 \\
\hline Present study & 2016 & India & Dry bones & 17.71 \\
\hline
\end{tabular}

The mean anterior height of the body in the present study is in agreement with the results of study by Singh R et al \& Patil Dhaval K. et al ${ }^{(12)}$ and is greater than the values reported by Tan et al and Kunkel ME et al. Thus, a comprehensive data set has been presented which provides quantitative anatomy of vertebral body of typical thoracic vertebrae. The differences in the results of the present study and those of the previous studies with respect to some of the parameters may be due to differences in race, ethnicity, environmental factors as well as methods used for the studies. These findings strengthen the recommendations by Roop Singh et al ${ }^{(8)}$ for modification in spinal surgery instrumentations in accordance with the morphometric data obtained from Indian population.

\section{References}

[1]. Standring S. et al. The Back. In: Newell RL, editor. Gray's Anatomy: Anatomical Basis of Clinical Practice. 40th ed. Edinburgh: Elsevier Churchill Livingstone; 2008: 712724.

[2]. Snell RS. Clinical Anatomy by Systems. Philadelphia: Wolters Kluwer HealthLippincott Williams \& Wilkins; 2006:170

[3]. Pal GP, Routal RV. A study of weight transmission through the cervical and upper thoracic regions of the vertebral column in man. Journal of Anatomy 1986; 148:245261.

[4]. Pal GP, Routal RV. Transmission of weight through the lower thoracic and lumbar regions of the vertebral column in man. Journal of Anatomy 1987; 152:93-105.

[5]. Chaynes P, Sol JC, Vaysse P, Bécue J, Lagarrigue J. Vertebral pedicle anatomy in relation to pedicle screw fixation: a cadaver study. SurgRadiolAnat 2001; 23:85-90.

[6]. Panjabi MM, Takata K, Goel V, Federico D, Oxland T, Duranceau J, et al. Thoracic human vertebrae: quantitative threedimensional anatomy. Spine (Phila Pa 1976) 1991; 16:888-901.

[7]. Tan SH, Teo EC, Chua HC. Quantitative three-dimensional anatomy of cervical, thoracic and lumbar vertebrae of Chinese Singaporeans. Eur Spine J 2004;13:137-146

[8]. Singh R, Srivastva S, Prasath C, Rohilla R, Siwach R, Magu N. Morphometric measurements of cadaveric thoracic spine in Indian population and its clinical applications. Asian Spine J 2011; 5(1):2034.

[9]. Gupta R, Singla RK. Thoracolumbar neural canal - a morphometric and morphological study in North Indian population. J Pharm Biomed Sci 2011; 11(11):1-7.

[10]. Kunkel M E, Herkommer A, Reinehr M, Böckers T M, Wilke HJ. Morphometric analysis of the relationships between intervertebral disc and vertebral body heights: an anatomical and radiographic study of the human thoracic spine. J Anat 2011;219:375-380.

[11]. Berry JL, Moran JM, Berg WS, Steffee AD. A morphometric study of human lumbar and selected thoracic vertebrae. Spine (Phila Pa 1976) 1987; 12:362-367.

[12]. DR. PATIL DHAVAL K. et. Al, A Morphometric Study of the Vertebral Body in Dry Human Typical Thoracic Vertebrae. IJAPB: Volume: 1; Issue: 1; October 2014

Fig.1- Illustration showing measurement of the anteroposterior distance and transverse diameter (superior surface) in typical thoracic vertebra.

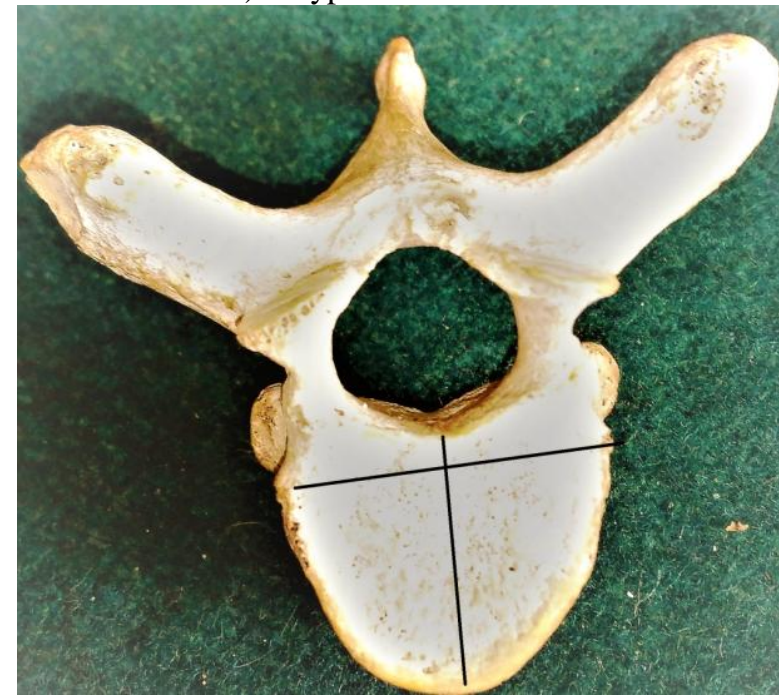


A Morphometric Study Of Dry Human Typical Thoracic Vertebral Body In Telangana Region.

Fig.2- Illustration showing measurement of anterior and Rt \& Lt lateral height of the body in typical thoracic vertebra.

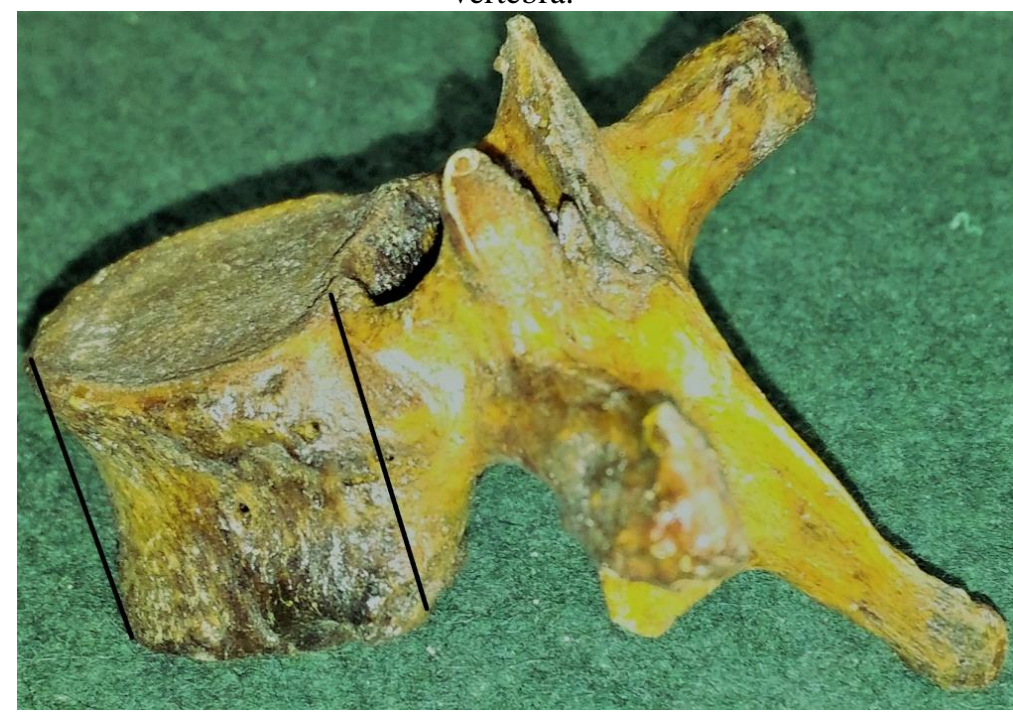

